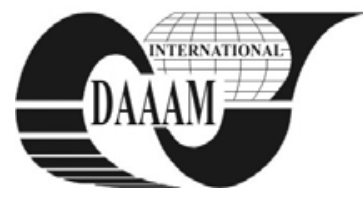

\title{
HEAVY MACHINE-TOOLS: MODULARIZED HYDRAULIC INSTALLATIONS
}

\author{
PRODAN, D[an]; BUCURESTEANU, A[nca] M[onica] \& BALAN, E[milia]
}

\begin{abstract}
This paperwork presents the hydraulic systems most frequently used in driving of heavy machine tools and their possibilities of being modularized. The systems presented mainly concern CNC heavy machine-tools that have been manufactured within the last 20 years. The modularization of these systems allows a faster designing and manufacturing of the machine-tools with less cost.
\end{abstract}

Key words: heavy machine-tools, modularized, hydraulic

\section{INTRODUCTION}

The machine-tools approached within this article are: heavy horizontal lathes (NL) and vertical lathes (VL), gantry milling machines $(G)$, horizontal boring mills with or without quill (AF or AFP) and some special heavy machines (SMU).

At present, the hydraulic installations designed for these machines belong to some systems that are not involved directly in the driving of the generating kinematic chains (Sandu, 2008), such as the main and the feed kinematic chains.

\section{CLASSIFICATION OF THE HYDRAULIC DRIVING SYSTEMS USED ON HEAVY MACHINE-TOOLS}

For the machine-tools mentioned above, the hydraulic drives are often met under the working conditions shown below:

1. Toolholder clamping/unclamping; working pressure at source: $(60-160)$ bar; required flow at source: $6 \mathrm{l} / \mathrm{min}$; working mode: intermittent or continuous. It is used for all the machines; most of them have hydraulic unclamping and mechanical clamping.

2. Locking and unlocking on axes; working pressure at source: $(30-210)$ bar; required flow at source: $(2-10)$ 1/min; working mode: intermittent or continuous. It is used for all the machines; CNC machine-tools have hydraulic locking and unlocking on axes.

3. Switch of speed range at the gearbox; working pressure at source: $(30-50)$ bar; required flow at source: $(10-16)$ 1/min; working mode: preferably intermittent. It is used for all the machines that have not typified gearbox with electric switching on and off.

4. Backlash compensation; working pressure at source: (15 60) bar; required flow at source: (2 - 16) l/min; working mode: continuous. It is met to the majority of the machines for the axes provide with pinion-rack or pinion-crown gear mechanisms.

5. Indexers drive; working pressure at source: $(30$ - 80) bar; required flow at source: $6 \mathrm{l} / \mathrm{min}$; working mode: intermittent. It is used for vertical lathes (VL), gantry milling machines $(\mathrm{G})$ only if the crossrail movement is not a working axis.

6. Weight balancing on vertical direction; working pressure at source: $(30$ - 120) bar; required flow at source: $(10$ - 120) 1/min; working mode: continuous. Solution preferred to all CNC machine-tools.

7. Compensation of geometric errors; working pressure at source: $>100$ bar; required flow at source: $(2-10) \mathrm{l} / \mathrm{min}$; working mode: continuous. It is met to the AFP machines.

8. Hydrostatic bearing; working pressure at source: $(50-60)$ bar; required flow at source: $(6$ - 60) l/min; working mode: continuous. It is met to the AFP, G, VL (with table over $5000 \mathrm{~mm}$ ). Excepting the VL, it is about hydrostatic system on feed kinematic chains. For large VL it is on main kinematic chain for turning and on feed kinematic chains for milling.

At present, for the CNC heavy machine-tools manufactured in Romania, the following associations of functions can be obtained: 1,2 and 5 to ( $80-100$ bar); 2, 3 and 5 to (30 - 40) bar; 4 singular at $(15-60)$ bar, depending on the applied solution; 6 singular at $(80-110)$ bar with pump with pressure regulator; 7 singular at 100 bar with proportional reducing valve; 8 singular, possible with drain lubrication, with pressure adjustment or constant flow.

The associations above have taken into consideration the operating mode. If the machine is provided with a gearbox which does not require a hydraulic switching of the speed range (Prodan, 2010) and if the sealing of the hydraulic cylinders allows it, then the association 1,2 and 5 can be made at pressures up to 120 bar. The usage of an accumulator and a precontrol system, such the one in Figure 1, leads to a reduced consumption of energy and remove the risk of overheating. The possibility of locating the tank and the options of the cable and hoses carrier chains are decisive when selecting this variant. When accomplishing the functions, the pre-control coupling is recommended (directional control valve 1DV1).

The following notations have been used in Figure 1: PCF pump with constant capacity; CV - check valves; 1DV1 single electromagnet directional control valve; 1DV2 - twoelectromagnet directional control valve; PS1-9 - pressure switches; S1-7 - bobine; Ac - accumulator; C1, C2 - manually actuated isolation valves; PV1, PV2 - pressure valves; M1, M2 - manometers; L1 L2 - limit switches.

Usually, a $4 \mathrm{~cm}^{3}$ pump is enough. The adjustments will be made according to the maximum pressure adjusted at the pressure valve.

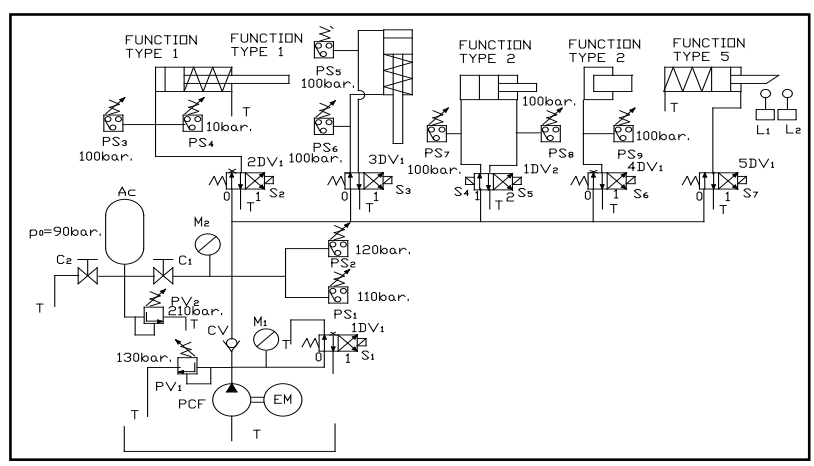

Fig. 1. Hydraulic installation with accumulator 
If this pressure is $p_{\mathrm{PV} 1}=130 \mathrm{bar}$, then a possible adjustment is the following: $\mathrm{PS} 1$ to $p_{\mathrm{PV} 1}=20 \mathrm{bar}$, $\mathrm{PS} 2$ to $p_{\mathrm{PV} 1}=10 \mathrm{bar}$, PS3, PS5, PS6, PS7, PS8 and PS9 to $p_{\mathrm{VP} 1}=30$ bar and PS4 to 10 bar.

If the association 2, 3, 5 is adopted, then the principle diagram in Figure 2 can be used, depending on the pressure required for actuating the sliding gears.

The notations above have been kept in Figure 2. The reducing valve is adjusted to a value with at least 10 bar smaller then the main line pressure (Prodan et al., 2005).

For backlash compensation within the feed kinematic chains that are using pinion-rack or pinion-crown gear systems as the final mechanisms (Perovic, 2006), independent hydraulic system is represented in Figure 3.

The electric motor driving the pump usually has a power no bigger than $2.2 \mathrm{~kW}$. At present, for the last generation machinetools, systems with two feed motoreducers working opposite are provided for backlash compensation (Prodan, 2010).

The balancing of the heavy weights that move on vertical direction is probably the most important hydraulic function designed for the heavy machine-tools.

For flows up to $100 \mathrm{l} / \mathrm{min}$ and pressures of 120 bar maximum, a more often used solution is the one represented in Figure 4. The pump with pressure regulator is to be noticed. This pump usually has blades or axial pistons. For the last one, the design with tilted disk is preferred (Prodan et al., 2005) in order to have a response time as short as possible.

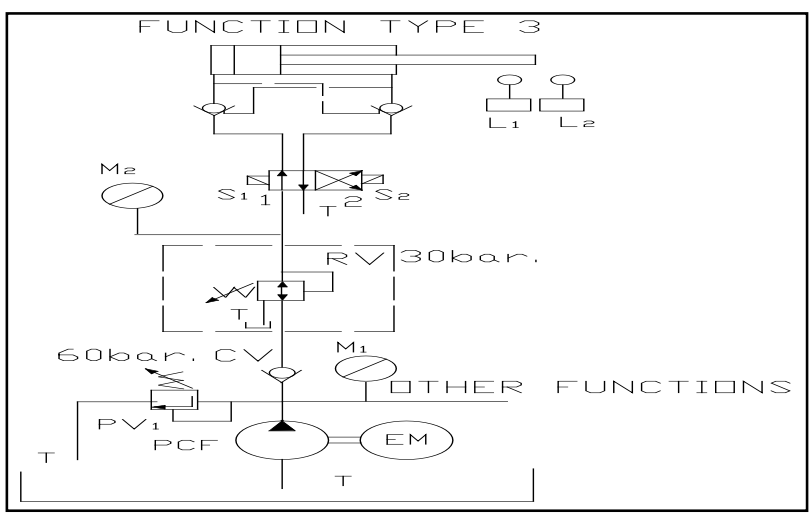

Fig. 2. The installation for actuating the sliding gears

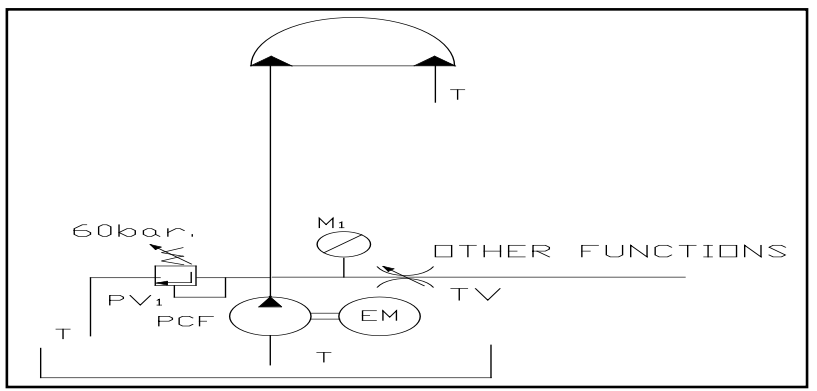

Fig. 3. Hydraulic system for backlash compensation

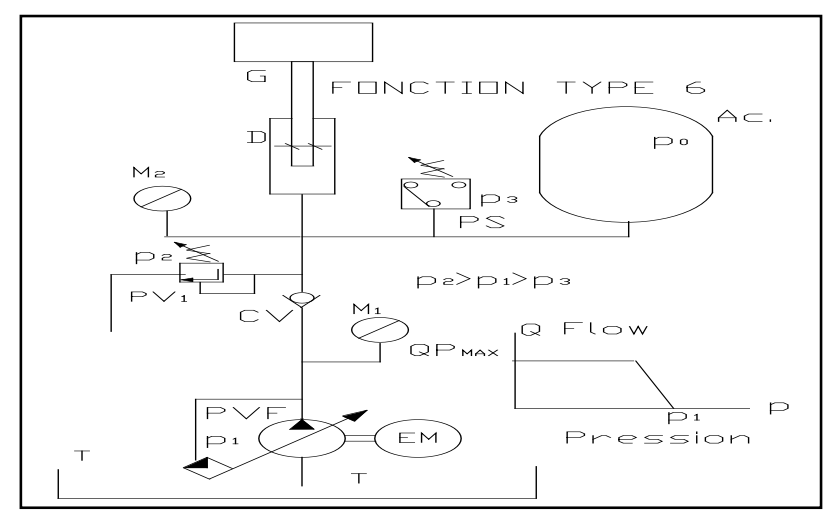

Fig. 4. The balancing system

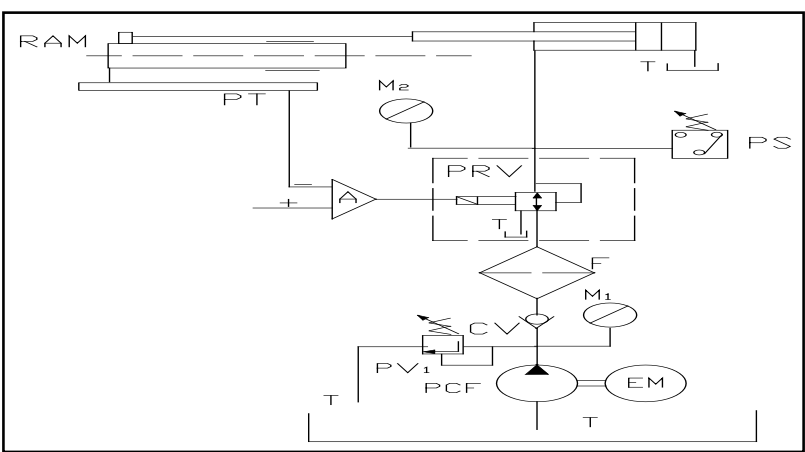

Fig. 5. System of compensating the deflection of the ram

The pump PVF has variable flow and the pressure regulator is adjusted to the pressure $p_{1}$. The curve of these pumps is shown on the right-hand of the figure. When the weight $G$ descends, the check valve $\mathrm{CV}$ gets closed and the oil is discharged through the pressure valve $\mathrm{PV}_{1}$. The pressure switch PS adjusted to the pressure $p_{3}$ confirms the balancing. The accumulator Ac ensures the flow peaks required when starting the feed kinematic chain (Bucuresteanu, 2003).

Upon the information provided by one of the position transducers, the compensation of the geometrical errors can be made by means of the proportional reducing valves (Deaconescu, 2007). Figure 5 shows a system of compensating the deflection of the ram of a Horizontal Boring Mill AFP 180.

The circuit includes: the constant flow pump PCF, the pressure valve $\mathrm{PV}_{1}$, the check valve $\mathrm{CV}$, the proportional reducing valve PRV, position encoder PT, the pressure switch PS and the filtering system F.

The solutions that are used within the hydrostatic bearing are of two types: with constant pressure and with constant flow (Perovic, 2006). The major difference between the two systems is represented by the type of the equipment that is used to adjust the load being taken over by each hydrostatic pocket: throttle valve or pressure regulator (Bucuresteanu, 2003).

\section{CONCLUSION}

The hydraulic installations of the CNC heavy machine-tools can be modularized for accomplishing different specific functions. These functions can be ensured by one or several hydraulic units. The componence and location of the hydraulic units depend on the hydraulic equipment and the particularity of the machine-tools. The working pressure is one of the main criteria of modularization. When drawing up the real schemes the constructive particularities of the machine-tools should be considered in such way to avoid using long hoses and cable and hoses carriers.

\section{REFERENCES}

Bucuresteanu, A. (2003). Hydraulic and Pneumatic Driving Systems, Printech Publisher House, ISBN 973-652-819-9, Bucharest

Deaconescu, T. (2007). Hydraulic Driving Systems, Transylvania University Publisher House, ISBN 878-973598-121-1, Brasov

Perovic, B. (2006). Handbuch Werkzeug-maschinen, HANSER Publisher House, ISBN 10:3-446-40602-6, Berlin

Prodan, D.; Duca, M.; Bucuresteanu, A. \& Dobrescu T. (2005). Hydrostatic Actuating. Organologie, AGIR Publisher House, ISBN 973-720-011-X, Bucharest

Prodan, D. (2010). Heavy Machine Tools. Mechanical and Hydraulic Systems, Printech Publisher House, ISBN 978978-606-521-474-2, Bucharest

Sandu, I. (2008). Treatise of Surfaces Generation Process, Romanian Academy Publisher House, ISBN 978-973-271730-1, Bucharest 